(C) Коллектив авторов, 2017

УДК 616.85:616.314]-07

DOI:10.23888/HMJ20173453-461

ДИНАМИКА ГЕМОДИНАМИЧЕСКИХ ПОКАЗАТЕЛЕЙ, САЛИВАЦИИ, а-АМИЛАЗНОЙ АКТИВНОСТИ У СТОМАТОЛОГИЧЕСКИХ БОЛЬНЫХ КАК БИОМАРКЕРОВ СТРЕССОВОЙ РЕАКТИВНОСТИ

\author{
А.В. СЕВБИТОВ ${ }^{1}$, А.В. ЮМАШЕВ ${ }^{1}$, Н.Е. МИТИН ${ }^{2}$, В.А. ПЕШКОВ ${ }^{2}$
}

Первый МГМУ им. И.М. Сеченова (Сеченовский Университет), ул. Трубецкая, 8/2, 119991, г. Москва, Российская Федерация (1)

Рязанский государственный медицинский университет им. акад. И.П. Павлова, ул. Высоковольтная, 9, 390026, г. Рязань, Российская Федерация (2)

Стоматофобия представляет собой незаурядное явление в практике врачастоматолога, отягощаюее актуальное состояние пациента и затрудняющее лечебнодиагностические интервенции. Выявление предикторов развития стресса и особенностей стрессовой реактивности пациентов предопределяет возможность превентивных манипуляций, направленных на снижение психоэмоционального дистресса больных. В работе произведена попытка выявления, оценки и квалификации биометрических показателей стрессовой реактивности пациентов, страдающих стоматологической патологией. Цель работы: оценить выраженность стрессовой реактивности у стоматологических больных на основании показателей артериального давления, скорости слюноотделения и активности $\alpha$-амилазы. Обследованы 30 пациентов, страдающих стоматологической патологией и проходивших лечение на базе клиники ортопедической стоматологии ПМГМУ им. И.М. Сеченова. Из них 18 женщин и 18 мужчин. Пациенты были разделены на три группы исследования согласно возрастной категории. Методы исследования: клинический, физикальные (лабораторный, тонометрический, функциональный), психодиагностический, статистический. Проводили: выявление ситутивной тревожности с помощью Методики диагностики самооценки тревожности Ч.Д. Спилбергера в модификации Ю.Л. Ханина; оценку скорости саливации методом сплевывания смешанной слюны; измерение скорости секреции слюны определяли путем деления количества слюны на время получения секрета; измерение активности $\alpha$-амилазы при помощи полуавтоматического биохимического анализатора Bio Chem SANTI спектрофотометрическим методом. Проведена оценка степени реактивной тревожности и ее корреляция с такими физиологическими показателями как показатели артериального давления, скорость слюноотделения и активность $\alpha$-амилазы как маркерами стрессовой реактивности у стоматологических больных. Исследована роль выявленных биомаркеров стресса в оценке состояния вегетативной нервной системы как одного из патофизиологических компонентов психоэмоционального напряжения. По данным исследования, лечение у врача-стоматолога выступило стрессогенным фактором для всех обследуе- 
мых пациентов. Наиболее уязвимыми категориями по отношению к стрессовому воздействию, явились испытуемые старших возрастных групп. Выявлено сокращение скорости слюноотделения после лечения у пациентов всех групп в два раза на фоне повышения активности $\alpha$-амилазы.

Ключевые слова: стрессовая реактивность, ситуативная тревожность, гемодинамика, $\alpha$-амилаза, саливация, биомаркеры стресса, стоматологическая патология.

\section{DYNAMICS OF HEMODYNAMIC VARIABLES, SALIVATION, a-AMYLASE ACTIVITY OF DENTAL PATIENTS AS BIOMARKERS OF STRESS REACTIVITY}

\section{A.V. SEVBITOV ${ }^{1}$, A.V. YUMASHEV ${ }^{1}$, N.E. MITIN ${ }^{2}$, V.A. PESHKOV ${ }^{2}$ \\ I.M. Sechenov First Moscow Medical University (Sechenovskiy University), Trubetskaya str., 8/2, 119991, Moscow, Russian Federation (1) \\ Ryazan State Medical University, Vysokovoltnaya str., 9, 390026, Ryazan, Russian Federation (2)}

Dental phobia extraordinary phenomenon in the practice of a dentist, aggravating the actual condition of the patient and complicating diagnostic and treatment interventions. Identifying the predictors of stress and features of stress reactivity of patients determines the possibility of preventive manipulations aimed at reducing the emotional distress of patients. The work attempted to identify, evaluation and certification of biometric indices of stress reactivity of patients suffering from dental pathology. The purpose of the work - to assess the severity of stress reactivity in dental patients on the basis of indicators of arterial pressure, the speed of salivation and the activity of $\alpha$-amylase. We examined 30 patients, who suffered from dental pathology and underwent treatment at the clinic of prosthetic dentistry of first Moscow state medical University them. I. M. Sechenov, we was examined. Of these, 18 women and 18 men. The patients was divided into three study groups according to age category. Research methods: clinical, physical (laboratory, tonometric, functional), psycho-diagnostic, and statistical. We conducted: identification situational anxiety using State-Trait Anxiety Inventory; the rate of salivation by the method of spitting the mixed saliva; measurement of the rate of saliva secretion was determined by dividing the number of saliva at the time of receiving the secret; measurement of activity of $\alpha$-amylase by using semi-automatic biochemical analyzer Bio Chem SANTI, spectrophotometric method. The level of reactive anxiety and its correlation with such physiological indicators as blood pressure, the speed of salivation and the activity of $\alpha$-amylase as markers of stress reactivity in dental patients was assess. The role of identified biomarkers of stress in assessment of the autonomic nervous system as one of the pathophysiological components of mental and emotional stress we investigated. According to the study, treatment dentist made stressful factor for all examined patients. The most vulnerable groups in relation to stress effects, were the subjects of older age groups. Identified the reduction in the rate of salivation after treatment in patients of all groups two times on the background of increasing the activity of $\alpha$-amylase.

Keywords: stress reactivity, situational anxiety, hemodynamics, $\alpha$-amylase, salivation, bio markers of stress, dental pathology.

Психоэмоциональный стресс выступает структурообразующей частью общего адаптационного синдрома - неспеци- фического ответа организма на воздействие стрессорных факторов - как физического, так и психологического характера - 
нарушающих его гомеостаз [1-3].

Согласно данным многочисленных отечественных и зарубежных исследований, острый и хронический стресс лежит в основе психоэмоциональных расстройств различного уровня. Ему принадлежит важнейшая роль в становлении соматоформных и психосоматических заболеваний [3-6].

В своей рутинной практике врачи различных специальностей нередко сталкиваются с нозогенно и ятрогенно обусловленными стрессовыми реакциями у пациентов и их нежелательными последствиями.

Одним из наиболее стрессогенных для пациентов выступает обследование и лечение у врача-стоматолога. Возникновение дистресса, ассоциированного с посещением стоматологического кабинета и квалифицируемого как стоматофобия, наиболее часто обусловлено следующими факторами:

- спецификой процедуры осмотра и лечения, требующей близкого контакта пациента с врачом, нарушающего границы личного пространства;

- вовлечение в процесс обследования и лечения интимных зон ротовой полости;

- необходимостью длительно занимать вынужденное положение во время врачебных манипуляций;

- специфическими аудиальными и ольфакторными раздражителями обусловленными резкими аппаратными звуками и медикаментозными запахами;

- ожиданием дискомфорта и болевых ощущений;

- имеющимся негативным опытом стоматологического вмешательства.

Последствиями перенесенного пациентом на медицинском приеме психоэмоционального перенапряжения могут быть уклонение от последующего планового посещения врача, невыполнение медицинских рекомендаций, что чревато удлинением срока лечения, а также повышением частоты осложнений вследствие нарушения комплаенса к терапии. Бурная психомоторная реакция, сопровождающая острый стресс во время врачебных манипуляций, может стать причиной нанесения травмы пациенту или врачу [7]. Кроме того, активация симпатического отдела нервной системы и повышение уровня катехоламинов в крови нередко являются причиной ухудшения качества анестезии, тем самым значительно усложняется работа врача и усугубляется состояние пациента. Данные нейрогормональные изменения способны повлечь за собой учащение сердцебиения, повышение уровня артериального давления больных, что на фоне имеющейся соматоневрологической патологии увеличивает вероятность развития неотложных состояний.

В связи с вышеизложенным, специфика стоматологического приема диктует необходимость тщательного исследования психоэмоционального статуса пациента при первичном и повторных обращениях, a также его оценку в динамике с целью профилактики и своевременной коррекции стрессовых состояний [8]. В то время как стресс-реакция, развивающаяся на физическом уровне, имеет универсальный, можно сказать стереотипный характер, проявления дезадаптации в эмоциональной и психической сферах по своей форме и силе выраженности отличаются широкой вариабельностью, что предъявляет особые требования к навыкам их диагностики.

Выраженность проявлений психоэмоционального стресса оценивают различными методами: путем определения степени напряжения отдельных мышечных групп, скорости простой и сложной сенсомоторных реакций, состояния эмоциональной сферы при помощи специальных психологических опросников и проективных тестов.

Однако существенным недостатком большинства предлагаемых методик является то, что они, как правило, не учитывают метаболические изменения, развивающиеся в тканях и органах в условиях адаптационного синдрома.

Доступным материалом для оценки изменений на органном и системном уровнях служат биологические жидкости: плазма крови, моча и, в последнее время,-слюна, которая также выступает в качестве информативного показателя наличия пси- 
хоэмоциональной реакции. Это объясняется тем, что в ней содержится большое количество белков, в том числе ферментов, которые выступают индикаторами биологических процессов - биомаркерами [9-11].

В этом контексте в качестве биомаркеров стресса, на наш взгляд, могут выступать скорость слюноотделения и секреция $\alpha$-амилазы - секреторного белка околоушных и поднижнечелюстных желез.

Исследования показывают, что эмоциональный стресс вызывает увеличение содержания катехоламинов в плазме крови [12].

Известно также, что количество образующегося секрета слюнных желез и содержание $\alpha$-амилазы в слюне коррелирует с уровнем катехоламинов. Симпатические волокна, иннервирующие слюнные железы, под действием стрессора выделяют адреналин и норадреналин, которые изменяют концентрацию вторичного посредника 3',5'-цАМФ при передаче гормонального сигнала. Это, в свою очередь, приводит к увеличению внутриклеточной концентрации цАМФ-нейромедиатора, стимулирующего выделение секреторных гранул, содержащих $\alpha$-амилазу.

В литературе отмечено, что нейрогормональная стимуляция симпатических сосудодвигательных нервов наряду с подавлением активности парасимпатического отдела вегетативной нервной системы, выполняющего стабилизирующую функцию, при стрессе негативно сказывается на состоянии сердечно-сосудистой системы и гемодинамических показателях [13].

Вышеперечисленное обуславливает актуальность и значимость изучения стрессовой реактивности и установления маркеров стресса с целью дальнейшей разработки превентивных мер его психопрофилактики.

\section{Цель исследования}

Оценить выраженность стрессовой реактивности у стоматологических больных на основании показателей артериального давления, скорости слюноотделения и активности $\alpha$-амилазы.

\section{Материалы и методы}

На базе клиники ортопедической стоматологии ПМГМУ им. И.М. Сеченова в условиях соблюдения принципов этики и деонтологии, на основании осознанного информированного согласия были обследованы 36 пациентов разного возраста, из них 18 женщин и 18 мужчин. По критерию возраста все пациенты были разделены на 3 группы. Первую группу исследования (ГИ-1) составили 10 пациенты возрастом от 18 до 30 лет. Во вторую группу исследования (ГИ-2) вошли 11 человек в возрасте от 30 до 40 лет. В третью группу исследования (ГИ-3) были объединены 15 человек в возрасте от 40 лет и выше.

Стрессовую реактивность оценивали путем определения до и после стоматологического лечения ситуативной тревожности, показателей сердечно-сосудистой системы посредством измерения систолического и диастолического артериального давления, скорости слюноотделения и активности слюнной $\alpha$-амилазы [9].

Методы исследования: клинический, физикальные (лабораторный, тонометрический, функциональный), психодиагностический, статистический.

Выявление и квантивикацию ситутивной тревожности проводили с помощью Методики диагностики самооценки тревожности Ч.Д. Спилбергера в модификаций Ю.Л. Ханина (State-Trait Anxiety Inventory, STAI, Ch. Spielberger et al., 1970, адаптированная Ю.Л. Ханиным, 1976).

Оценку скорости саливации проводили методом сплевывания смешанной слюны в стеклянные пробирки в течение 5 минут до и после лечения. Скорость секреции слюны определяли путем деления количества слюны на время получения секрета.

Активность $\alpha$-амилазы в смешанной слюне измеряли при помощи полуавтоматического биохимического анализатора Bio Chem SANTI спектрофотометрическим методом. Использовались реактивы фирмы «Вектор-Бест» (Россия).

Показатели гемодинамики определяли путем измерения систолического и 
диастолического артериального давления с применением полуавтоматического тонометра Microlife BP A6 PC.

Статистическая обработка результатов осуществлялась с применением методов параметрической и непараметрической статистики (вычисление среднеарифметических значений (М), среднеквадратического отклонения (стандартного отклонения, m), критерия ранговой корреляции Спирмена (r), U-критерия Манна-Уитни). Различия считались достоверными при $\mathrm{p} \leq 0,05$.

\section{Результаты и их обсуждение}

В результате исследования с помощью опросника STAI отмечены завышенные показатели ситуативной тревожности у пациентов всех групп исследования в преддверии стоматологического лечения с достоверной тенденцией к эксзацербации. Средний уровень ситуативной тревожности по группам во время первого измерения имел следующее распределение: ГИ-1

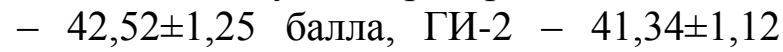
баллов, ГИ-3 - 43,34 $\pm 0,98$ баллов.

Выявленные особенности подтверждают стрессогенный характер самого факта необходимости посещения стоматологического кабинета [14] и ожидания стоматологических манипуляций.

Во всех группах уровень ситуативной тревожности, зафиксированный после лечения, достоверно превышал данные первого измерения. Распределение по группам имело следующее представление: ГИ-1 -

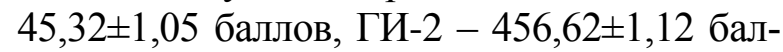
лов, ГИ-3 - 69,74 $\pm 0,98$ баллов. Между показателями мужчин и женщин достоверные отличия отсутствовали.

Как видно из вышеприведенных данных, в возрастной группе от 40 лет и выше (ГИ-3) показатели ситуативной тревожности после лечения достоверно превышали данные в ГИ-1 и ГИ-2.

При этом данные дополнительного анкетирования продемонстрировали анозогнозические тенденции в представлениях пациентов стоматологического кабинета в отношении собственного психоэмоционального состояния в контексте стоматоло- гического лечения и тенденции к деструктивным аутотерапевтическим паттернам.

Так, согласно результатам анкетирования, повышенную стрессовую готовность в связи с необходимостью проведения лечения высказали всего 25\% исследуемых, $31 \%$ опрашиваемых продемонстрировали склонность к появлению психоэмоциональной реакции на лечение (реакции тревожномнительного типа). При этом 16\% исследуемых признались, что для преодоления стресса используют такие методы профилактики и аутотерапии стресса как употребление алкоголя и табакокурение, 34\% конструктивные методы борьбы со стрессовыми ситуациями, в том числе сон, общение с друзьями, физические нагрузки, смену трудовой деятельности.

Измерение артериального давления у пациентов продемонстрировало максимальные показатели уровня систолического давления как до, так и после окончания лечения в возрастной группе от 40 лет и

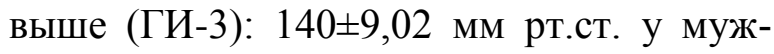
чин, $139 \pm 5,59$ мм рт.ст. у женщин при первом измерении и 155 $\pm 5,34$ мм рт.ст. у мужчин, $159 \pm 8,12$ мм рт.ст. у женщин при повторном измерении, что достоверно отличало этих пациентов от ГИ-1 и ГИ-2. Достоверные отличия между показателями систолического давления мужчин и женщин ГИ-3 отсутствовали.

Минимальный уровень систолического давления в течение всего эксперимента наблюдался в возрастной группе от 18 до 30 лет (ГИ-1): находясь в пределах нормативных значений уровень систолического давления достоверно не изменялся при повторном исследовании и составлял у женщин 124 $\pm 3,81$ мм рт.ст, у мужчин $125 \pm 2,63$ мм рт.ст. Достоверные отличия между показателями систолического давления мужчин и женщин ГИ-1 отсутствовали.

Отмечены достоверные отличия в скорости слюноотделения до и после лечения у пациентов всех групп. В ГИ-1, ГИ-2 и ГИ-3 до лечения скорость слюноотделения находилась в пределах физиологической нормы (0,2-0,3 мл/мин); сразу после лечения отмечалось достоверное 
сокращение скорости слюноотделения в два раза (до 0,1-0,15 мл/мин). Достоверные отличия между группами исследовании отсутствовали.

Измерение активности $\alpha$-амилазы в ходе эксперимента позволило установить, что под действием стрессорного фактора на приеме у врача-стоматолога активность этого фермента достоверно менялась. Так, у 56\% испытуемых наблюдалось повышение активности $\alpha$-амилазы после лечения, при этом наиболее значимые сдвиги имели место среди женщин всех возрастных групп и у мужчин ГИ-3.

\section{Выводы}

Согласно данным исследования, лечение у врача-стоматолога выступило стрессогенным фактором для всех обследуемых пациентов. Наиболее уязвимыми категориями по отношению к стрессовому воздействию, явились испытуемые старших возрастных групп (пациенты в возрасте от 40 лет и выше). У этих пациентов стресс, обусловленный стоматологическими манипуляциями, проявлялся не только очень высоким уровнем ситуативной тревожности, но и повышением показателей систолического артериального давления (на 16士3,56 мм рт.ст. от исходного).

Выявлено сокращение скорости слюноотделения после лечения у пациентов всех групп в два раза на фоне повышения активности $\alpha$-амилазы, что может быть использовано в качестве биомаркера стресса.

Патофизиологическое объяснение этого феномена лежит в плоскости нейрорегуляции белков. Синтез белков слюнных желез регулируется циклическим аденозинмонофосфатом, образующимся в

\section{Литература}

1. Щербатых Ю.В. Психология стресса и методы коррекции. СПб.: Питер, 2007. $256 \mathrm{c}$.

2. Wamsteeker Cusulin J.I., Bains J.S. Embedded synaptic feedback in the neuroendocrine stress axis // J. Neuroendocrinol. 2015. №27 (6). P. 481-486. результате взаимодействия адреналина с $\beta$-адренорецепторами, чем объясняется изменение скорости слюноотделения в стрессовой для организма ситуации.

Стресс, вызванный посещением врача-стоматолога, приводит к существенным перестройкам в системе нейрогормональной и вегетативной регуляции путем стимуляции активности симпатического отдела наряду с угнетением парасимпатического отдела вегетативной нервной системы.

Из вышеприведенного следует, что слюна является клинически информативной биологической жидкостью. Результаты настоящего исследования показывают, что качественные и количественные характеристики смешанной слюны человека существенно варьируют на фоне различных психоэмоциональных состояний, на фоне стресса отмечается существенное замедление скорости слюноотделения за счет нарушения баланса в вегетативной регуляции в сторону активации симпатического звена.

Выявленное увеличение секреции $\alpha-$ амилазы слюнными железами опосредовано обусловлено изменением концентрации 3',5'-цАМФ под действием катехоламинов, уровень которых возрастает в ответ на действие стрессовых факторов, что, в свою очередь, также активирует симпатическую нервную систему.

Таким образом, наряду с данными экспериментального исследования и показателями гемодинамики, скорость саливации и активность $\alpha$-амилазы слюны могут служить чувствительными биомаркерами стрессовых изменений в организме, объективно отражающими активность симпатического отдела вегетативной нервной системы.

\section{Конфликт интересов отсутствует.}

3. Shurlygina A.V, Galiamina A.G., Mel'nikova E.V., Panteleeva N.G., Tenditnik M.V., Trufakin V.A., Kudriavtseva NN. Effects of roncoleukin on immune parameters and mixed anxiety/depression state induced by chronic social defeat stress in male mice // Ross. Fiziol. Zh. Im. I.M. Sechenova. 2014. №100 (2). P. 201-214. 
4. Китаев-Смык Л.А. Психология стресса. Психологическая антропология стресса. М.: Академический проект. 2009. $943 \mathrm{c}$.

5. Misrani A., Tabassum S., Long C. Oxytocin system in neuropsychiatric disorders: Old concept, new insights // Sheng Li Xue Bao. 2017. №69 (2). P. 196-206.

6. Olive L.S. Youth psychological distress and intermediary markers of risk for CVD: The emerging field of pediatric psychocardiology // Atherosclerosis. 2017. №17. Р. 50-58.

7. Игидбашян В.М., Зюлькина Л.А., Суворова М.Н., Емелина Г.В., Кузнецова Н.К., Кавтаева Г.Г. Современные подходы к вопросам комплексного лечения воспалительных заболеваний пародонта // Coвременные проблемы науки и образования. 2015. №5. С. 299.

8. Харитонов Д.Ю., Митин Н.Е., Царькова Т.В. Социально-психологическая реабилитация пациентов после хирургических операций при несращениях губы, неба или сочетанных несращениях (обзор литературы) // Наука молодых (Eruditio Juvenium). 2015. №4. C. 134-138.

9. Морман Д., Хеллер Л. Физиология сердечно-сосудистой системы. СПб.: Питер. 2000. $256 \mathrm{c}$.

10. Севбитов А.В., Скатова Е.А., Дорофеев А.Е., Золотова Е.В. Оценка восприятия боли пациентами пожилого возраста с различным психоэмоциональным статусом в послеоперационном периоде, проходившими амбулаторный хирургический стоматологический прием // Фарматека. 2013. №S4. C. 26-27.

11. Севбитов А.В., Митин Н.Е., Браго А.С., Михальченко Д.В., Юмашев А.В., Кузнецова М.Ю., Шакарьянц А.А., Стоматологические заболевания. Ростов-наДону.: Феникс, 2016. 158 с.

12. Wilson T.E. Renal sympathetic nerve, blood flow, and epithelial transport responses to thermal stress // Auton Neurosci. 2017. №204. P. 25-34.

13. Иорданишвили А.К., Бельских О.А., Карев Ф.А., Тишков Д.С., Музыкин М.И., Либих Д.А. Функциональные пока- затели вкусовой рецепции при хронических заболеваниях почек, кишечника и эндокринной патологии // Вестник Волгоградского государственного медицинского университета. 2016. №2 (58). С. 81-84.

14. Митин Н.Е., Васильева Т.А., Васильев Е.В. Методика определения жевательной эффективности с применением оригинальной компьютерной программы на основе методов анализа многомерных данных // Российский медико-биологический вестник имени академика И.П. Павлова. 2016. №1. С. 129-133.

\section{References}

1. Shcherbatykh YuV. Psikhologiya stressa i metody korrektsii [Psychology of stress and methods of correction]. SPb.: $\mathrm{Pe}-$ ter; 2007. 256 p. (in Russian)

2. Wamsteeker Cusulin JI, Bains JS. Embedded synaptic feedback in the neuroendocrine stress axis. J. Neuroendocrinol. 2015; 27 (6): 481-6.

3. Shurlygina AV, Galiamina AG, Mel'nikova EV, Panteleeva NG., Tenditnik MV, Trufakin VA, Kudriavtseva NN. Effects of roncoleukin on immune parameters and mixed anxiety/depression state induced by chronic social defeat stress in male mice. Ross. Fiziol. Zh. im. I.M. Sechenova. 2014; 100 (2): 201-14. (in Russian)

4. Kitaev-Smyk LA. Psikhologiya stressa. Psikhologicheskaya antropologiya stressa [The psychology of stress. Psychological anthropology of stress]. Moscow: Academic project; 2009.943 p. (in Russian)

5. Misrani A, Tabassum S, Long C. Oxytocin system in neuropsychiatric disorders: Old concept, new insights. Sheng $\mathrm{Li}$ Хие Bao. 2017; 69 (2): 196-206.

6. Olive LS. Youth psychological distress and intermediary markers of risk for CVD: The emerging field of pediatric psychocardiology. Atherosclerosis. 2017; 17: 50-8.

7. Igidbashyan VM, Zyul'kina LA, Suvorova MN, Emelina GV, Kuznetsova NK, Kavtaeva GG. Sovremennye podkhody $\mathrm{k}$ voprosam kompleksnogo lecheniya vospalitel'nykh zabolevaniy parodonta [Modern approaches to the questions of complex treatment of inflammatoty diseases 
of a parodont]. Sovremennye problemy nauki i obrazovaniya [Modern problems of science and education]. 2015. 5: 299. (in Russian)

8. Kharitonov DYu, Mitin NE, Tsar'kova TV. Sotsial'no-psikhologicheskaya reabilitatsiya patsientov posle khirurgicheskikh operatsiy pri nesrashcheniyakh guby, neba ili sochetannykh nesrashcheniyakh (obzor literatury) [Socio-psycholigical rehabilitation of patients after surgery of surgery on patients with cleeft lip, cleft palate or both (review)]. Nauka molodykh [Eruditio Juvenium]. 2015. 4: 134-8. (in Russian)

9. Morman D, Kheller L. Fiziologiya serdechno-sosudistoy sistemy [Physiology of the cardiovascular system]. SPb.: Peter; 2000. 256 p. (in Russian)

10. Sevbitov AV, Skatova EA, Doro-feev AE, Zolotova EV. Otsenka vospriyatiya boli patsientami pozhilogo vozrasta $\mathrm{s}$ razlichnym psikhoemotsional'nym statusom v posleoperatsionnom periode, prokhodivshimi ambulatornyy khirurgicheskiy stomatologicheskiy priem [Evaluation of the perception of pain by elderly patients with different psychoemotional status in the postoperative period, held an outpatient dental reception]. Farmateka [Pharmateca]. 2013. (S4): 26-7. (in Russian)

11. Sevbitov AV [et al.]. Stomatologicheskie zabolevaniya [Dental disease]. Rostov-on-don.: Phoenix; 2016. 158 p. (in Russian)

12. Wilson TE. Renal sympathetic nerve, blood flow, and epithelial transport responses to thermal stress. Auton Neurosci. 2017. 204: 25-34.

13. Iordanishvili AK, Bel'skikh OA, Karev FA, Tishkov DS, Muzykin MI, Libikh DA. Funktsional'nye pokazateli vkusovoy retseptsii pri khronicheskikh zabolevaniyakh pochek, kishechnika i endokrinnoy patologii [Unctional indicators of gustatory reception in chronic renal, intestinal and endocrine diseases]. Vestnik Volgogradskogo gosudarstvennogo meditsinskogo universiteta [Vestnik of Volgograd state medical University]. 2016. 2 (58): 81-4. (in Russian)

14. Mitin NE, Vasil'eva TA, Vasil'ev EV. Metodika opredeleniya zhevatel'noy effektivnosti $s$ primeneniem original'noy komp'yuternoy programmy na osnove metodov analiza mnogomernykh dannykh [The chewing efficiency determining method based on application of original computer program using multivariate data analysis]. Rossijskij mediko-biologicheskij vestnik imeni akademika I.P. Pavlova [I.P. Pavlov Russian Medical Biological Herald]. 2016. 1: 129-33. (in Russian)

\section{СВЕДЕНИЯ ОБ АВТОРАХ}

Севбитов А.В. - д.м.н., проф., зав. кафедрой пропедевтики стоматологических заболеваний Первого МГМУ им. И.М. Сеченова (Сеченовский Университет), г. Москва.

E-mail: avsevbotov@mail.ru

Юмашев А.В. - к.м.н., профессор кафедры ортопедической стоматологии стоматологического факультета Первого МГМУ им. И.М. Сеченова (Сеченовский Университет), г. Москва.

E-mail: umalex99@gmail.com

Митин Н.Е. - к.м.Н., доцент, зав. кафедрой ортопедической стоматологии и ортодонтии Рязанского государственного медицинского университета им. акад. И.П. Павлова, г. Рязань.

E-mail: Nimitin@yandex.ru

Пешков В.А. - к.м.н., доцент кафедры хирургической стоматологии, Рязанский государственный медицинский университет им. акад. И.П. Павлова, г. Рязань.

E-mail: pvstom@mail.ru 


\section{INFORMATION ABOUT THE AUTHORS}

Sevbitov A.V. - MD, PhD, DSc, professor, head of the department of propaedeutics of dental diseases I.M. Sechenov First Moscow Medical University (Sechenovskiy University), Moscow.

E-mail: avsevbotov@mail.ru

Yumashev A.V. - MD, PhD, professor, department of prosthodontics I. M. Sechenov First Moscow Medical University(Sechenovskiy University), Moscow.

E-mail: umalex99@gmail.com

Mitin N.E. - MD, PhD, assistant of professor, head of department of prosthetic dentistry and orthodontics Ryazan State Medical University, Ryazan.

E-mail: Nimitin@yandex.ru

Peshkov V.A. - MD, PhD, assistant of professor, department of surgical dentistry, Ryazan State Medical University, Ryazan.

E-mail: pvstom@mail.ru 